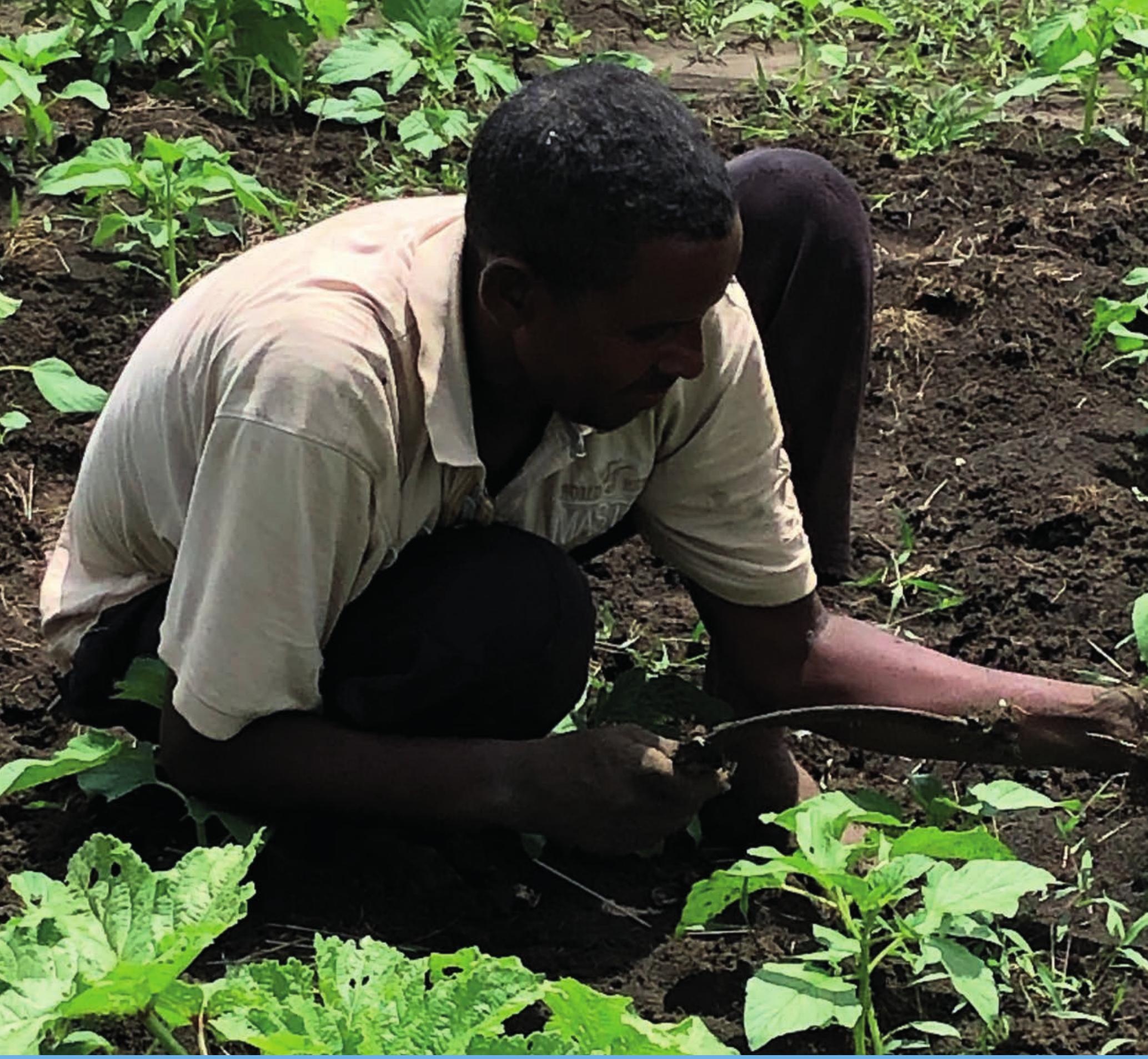





\section{Enhancing the resilience of the most vulnerable to (food) system shocks and stresses}

Synthesis paper

Joost Guijt and Nico Rozemeijer

Wageningen Centre for Development Innovation

Wageningen, March 2021 
Guijt, J. and N. Rozemeijer, 2021. Enhancing the resilience of the most vulnerable to (food) system shocks and stresses; Synthesis paper. Wageningen Centre for Development Innovation, Wageningen University \& Research. Report WCDI-21-140. Wageningen.

This report can be downloaded for free at https://doi.org/10.18174/543741 or at www.wur.eu/cdi (under publications).

The COVID-19 pandemic, and especially its responses such as lockdowns and transport restrictions shocked the world in 2020. Rapid assessments of the crisis showed that especially poor people were hit hard, facing immediate threats to their food and livelihood security. Varies UN agencies indicated that progress towards achieving SDGs is likely to be set back by decades. The people suffering from hunger is on the increase. With that context in mind a research was started at Wageningen University to assess impact of shocks such as COVID-19 on the most vulnerable groups of people, anticipated to suffer even more.

The research assignment developed three methodologies that allows both academic as well as support organisations to better understand how more vulnerable groups in society respond to crisis and what room there is to enhance their resilience. These methodologies were tested in two case studies (migrant labourers in the sesame sector in Ethiopia, jobless migrant youth from pastoral communities in Somaliland). Concepts and methodologies are described in seven reports that to a large extent build on each other.

1. Guijt, J. and N. Rozemeijer. Enhancing the resilience of those most vulnerable to (food) system shocks - Synthesis paper. https://doi.org/10.18174/543741

2. Wigboldus, S. and J. Jacobs. Enhancing the resilience of those most vulnerable to (food) system shocks - Clarifying and unpacking key concepts. https://doi.org/10.18174/543742

3. Wigboldus, S. and J. Jacobs. Enhancing the resilience of those most vulnerable to (food) system shocks - Towards a sense-making framework and assessment methodology. https://doi.org/10.18174/543743

4. Roo, N. de and J. van der Lee. Exploring vulnerability and resilience from a multifaceted and systemic perspective - Case studies in Ethiopia and Somaliland. https://doi.org/10.18174/543744

5. Wattel, C.J., M. Sopov and M.A.J.M. van Asseldonk. Responsible finance for vulnerable groups under COVID-19. https://doi.org/10.18174/543745

6. Wattel, C.J., M. Sopov and M.A.J.M. van Asseldonk. Finance for Resilience Tool (FORTE) - A rapid assessment tool. https://doi.org/10.18174/543746

7. Fonteijn, H., J. Groot and X. Guo. Analysing the resilience of food systems with scenario analyses and reverse stress tests - Concepts and an application on the Ethiopian sesame value chain.

https://doi.org/10.18174/543747

The authors would like to acknowledge funding from the Wageningen University \& Research "Food Security and Valuing Water programme" that is supported by the Dutch Ministry of Agriculture, Nature and Food Quality.

(C) 2021 Wageningen Centre for Development Innovation, part of the Stichting Wageningen Research. P.O. Box 88, 6700 AB Wageningen, The Netherlands. T + 31 (0)317 4868 00, E info.cdi@wur.nl, www.wur.eu/cdi.

\section{(cc) BY-NC}

The Wageningen Centre for Development Innovation uses a Creative Commons Attribution 4.0 (Netherlands) licence for its reports.

The user may copy, distribute and transmit the work and create derivative works. Third-party material that has been used in the work and to which intellectual property rights apply may not be used without prior permission of the third party concerned. The user must specify the name as stated by the author or licence holder of the work, but not in such a way as to give the impression that the work of the user or the way in which the work has been used are being endorsed. The user may not use this work for commercial purposes.

The Wageningen Centre for Development Innovation accepts no liability for any damage arising from the use of the results of this research or the application of the recommendations.

Report WCDI-21-140 


\section{Contents}

1 $\begin{array}{ll}\text { Background } & 9\end{array}$

$\begin{array}{lll}1.1 & \text { Why this research initiative? } & 9\end{array}$

$\begin{array}{ll}1.2 & \text { Purpose of this research? } \\ 1.3 & 10\end{array}$

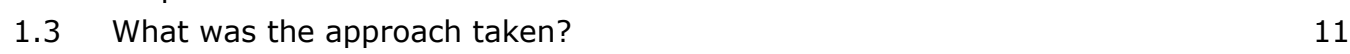

$\begin{array}{ll}1.4 & \text { What were the outputs? }\end{array}$

2

$\begin{array}{ll}\text { Overview of the research work } & 12\end{array}$

$2.1 \quad$ Clarifying and unpacking key concepts $\quad 12$

2.2 Design of a research framework to better understand vulnerability and coping strategies of the most vulnerable $\quad 12$

2.3 Testing the research framework in Ethiopia and Somaliland 13

$\begin{array}{lll}2.4 & \text { Responsible finance for vulnerable groups under COVID-19 } & 14\end{array}$

2.5 Using scenario analysis and reverse stress tests to analyse the resilience of food systems 



\section{Acknowledgements}

This synthesis paper is based on the work of colleagues jointly contributing to the Wageningen University research on Enhancing the resilience of the most vulnerable to (food) system shocks and stresses conducted between September 2020 and March 2021. Their work is captured in six papers referred to in section 1 below. We would like to thank Seerp Wigboldus, Judith Jacobs, Nina de Roo, Jan van der Lee, Cor Wattel, Monica Sopov, Marcel van Asseldonk, Hubert Fonteijn, Jim Groot and Xuezhen Guo for their efforts. Their work, in turn, relied greatly on valuable contributions from many people who themselves are working with, or are, the more vulnerable. Specific thanks to staff and partners of the Sesame Business network project in Ethiopia (https://www.wur. nl/nl/show/TheSesame-Business-Network-in-North-West-Ethiopia.htm), and the FNS-Repro project in Somaliland (https://www.wur.nl/en/Research-Results/Research-Institutes/centre-for-developmentinnovation/show-cdi/FNS-REPRO-building-food-system-resilience-in-protracted-crises.htm).

We hope this work helps in a small part to turn the eye on the often unseen groups. 


\section{List of abbreviations and acronyms}

$\begin{array}{ll}\text { FORTE } & \text { Finance for Resilience Tool } \\ \text { IMF } & \text { International Monetary Fund } \\ \text { LIMC } & \text { Low and Middle Income Countries } \\ \text { SDG } & \text { Sustainable Development Goal } \\ \text { UNFSS } & \text { United Nations Food Systems Summit }\end{array}$




\section{$1 \quad$ Background}

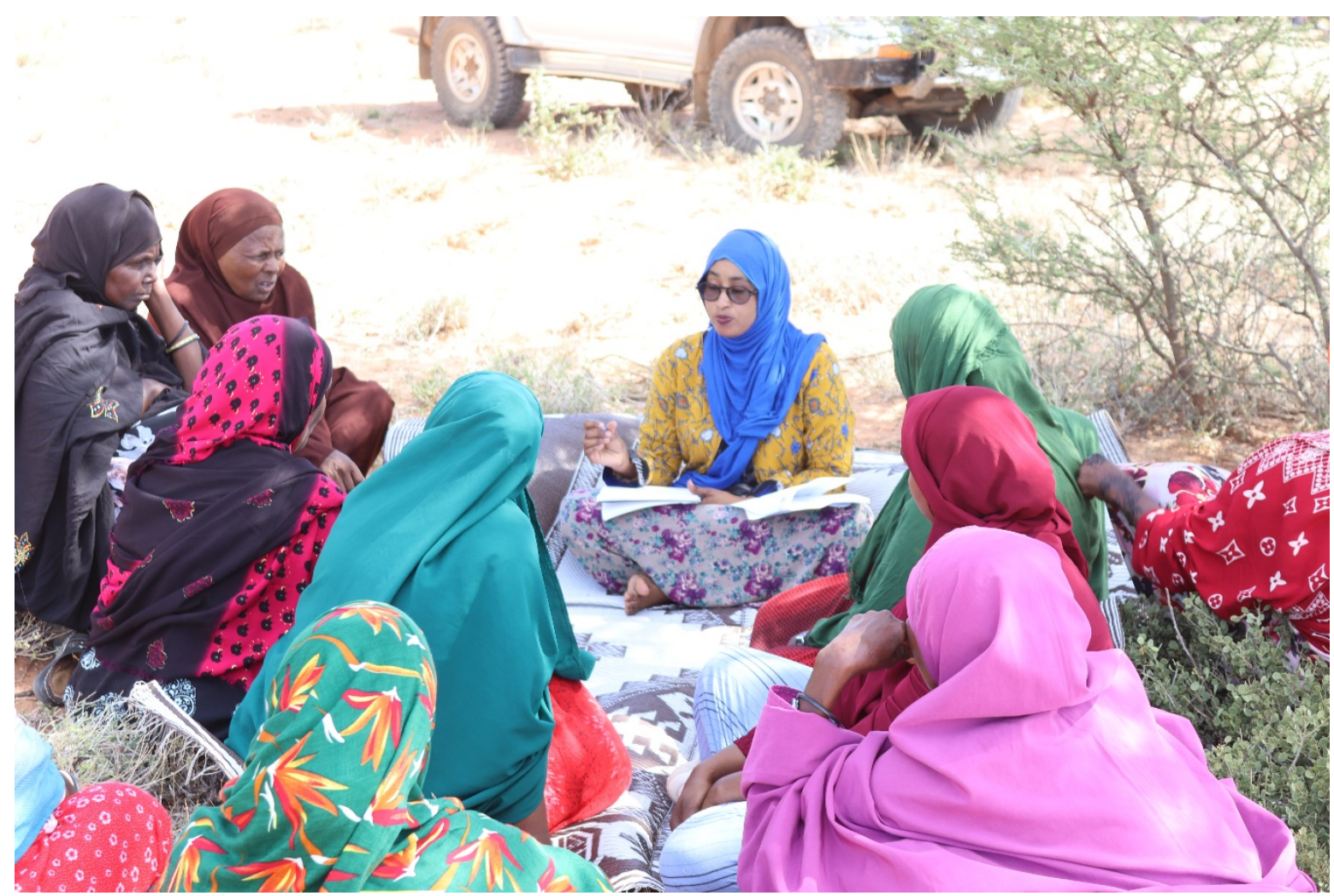

Credits: Khadar Mohamed (@FAO Somalia)

\subsection{Why this research initiative?}

The COVID-19 pandemic that hit the world in 2020 showed how a shock, and especially the responses to manage that shock, could so quickly affect economies and threaten food and livelihood security of many. While this is the daily reality of hundreds of millions facing drought, locusts, floods, civil war, etc, this is the first time for many years the entire world faced such far-reaching negative effects. Wageningen University conducted a series of country and sector rapid assessments ${ }^{1}$ to understand the effect of COVID-19 on food systems. Conclusions included: many SMEs had to lay-off workers; informal sector employment was seriously affected during lock-downs; transport bans and curfews resulted in loss of daily incomes; formal sector employment was hit due to decreased purchasing power of consumers; market closures and closure of schools affected poor households' access to food; price hikes made staple foods more expensive, expecting to make more people food-insecure in the near future. Effects of the pandemic on poor people were clear to see. It seemed also clear that the more vulnerable an actor group is to shocks, the more severe the impact. Various United Nations agencies have indicated that progress towards achieving the SDGs is likely to be set back by decades (Worldbank, 2020).

This research came from the premise that the most vulnerable groups of people are even more affected by shocks and crises of the COVID-19 kind. These are groups such as people selling on informal markets, casual labourers, landless farmers, migrant labourers, unemployed youth, just to mention a few. Such groups are in danger of being part of the 820 million people in the world who

1 https://www.wur.nl/en/Research-Results/Research-Institutes/centre-for-development-innovation/Our-ValuePropositions/Guiding-Sector-Transformation/The-effects-of-COVID-19-on-food-systems-rapid-assessments.htm 
suffer from hunger. These are also groups who tend to be rather invisible to formal institutions and are not easy to include in development support programmes (Criado Perez 2019; Woodhill 2020).

In the poorest countries where inequality is greater, economic slowdowns and downturns have a disproportionate effect on food security and nutrition for lower-income populations. Inequality increases the likelihood of severe food insecurity and this effect is 20 percent higher for low-income countries compared with middle-income countries. Income and wealth inequalities are also closely associated with undernutrition.

There is poor understanding of who exactly the most vulnerable are, how they operate in and depend on their local food systems, in what way they are vulnerable to stresses and shocks to the system, and whether these groups are considered in policy responses. Shocks to global food systems are many and likely to get worse. There is the current policy-induced shock in response to the COVID-19 pandemic but there are also natural system induced shocks (e.g droughts, locust and floods); and socio-political induced shocks such as rampant deforestation; a drinking water crisis, and war. We therefore need to be able to respond much more rapidly and effectively to such situations, while ensuring we address systemic issues that otherwise lead to the perpetuation of inequalities and vulnerability of too many people, especially the most vulnerable.

In this synthesis paper we provide an overview of the research work done between September 2020 and March 2021; to guide the reader through the different phases of the research, summarize key findings, and explain why we think these findings are important. We draw lessons on the applicability of the methodologies that were developed, and the work that would be required to deepen our understanding. We end by providing an overview of who we think could benefit from our research results.

\subsection{Purpose of this research?}

This research developed three methodologies that allow for evidence-based ways of understanding the dynamic realities of the most vulnerable, in order to be able to appropriately guide choices for responsible investments specifically as well as other intervention options. These methodologies were tested in two case studies: migrant labourers in the sesame sector in Ethiopia, and jobless migrant youth from pastoral communities in Somaliland.

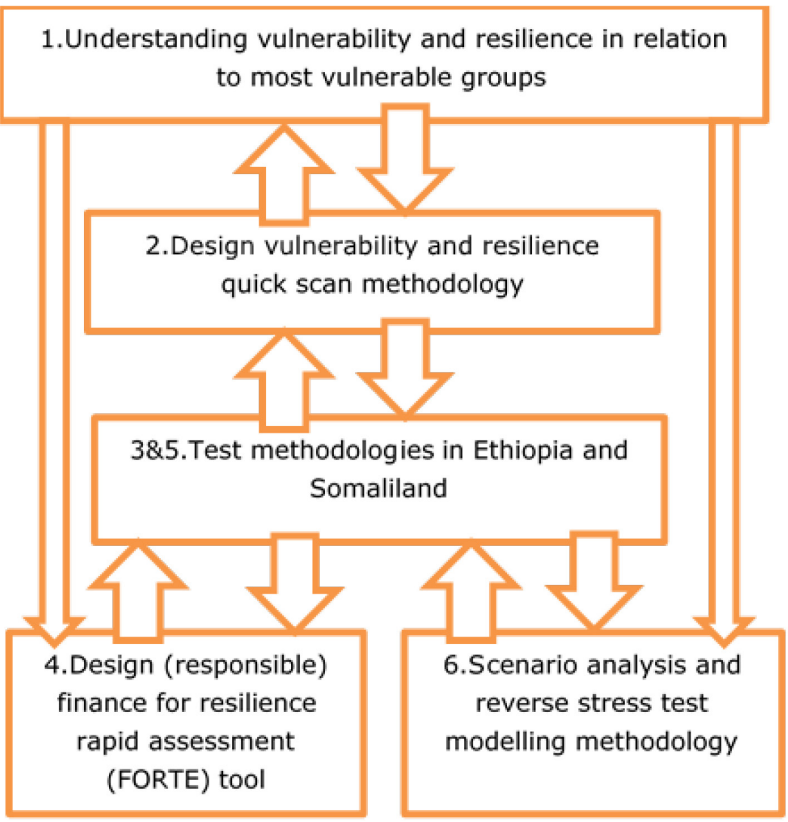

Figure 1 
Six research questions guided the work:

1. What is vulnerability and resilience, and how are these concepts relevant for the most vulnerable groups in society when trying to understand their livelihood systems?

2. How can we translate a conceptual understanding of vulnerability and resilience into a quick-scan research methodology to assess vulnerability of a specific target group in a specific context?

3. Testing of the research methodology in two case studies in Ethiopia and Somaliland.

4. A. Can responsible finance be a possible investment and policy option to support the most vulnerable in becoming more resilient to shocks; and what is "responsible" finance in this context? B. Can we develop a rapid assessment methodology to explore responsible finance options for a specific target group in a specific context?

5. Testing of the responsible finance options tool in two case studies in Ethiopia and Somaliland.

6. Can scenario analysis and reverse stress test modelling methodology help in analysing the resilience of a vulnerable actor group? Testing in a case study in Ethiopia.

\subsection{What was the approach taken?}

2020 was the year of COVID-19, and international travel was not possible because of the pandemic. Data collection for the research was therefore partly based on desk study and was partly organised from a distance. Long-term support programmes managed by Wageningen CDI were approached to help in data collection: the BENEFIT Sesame Business Network in Ethiopia ${ }^{2}$ and the Food and Nutrition Security Resilience Programme (FNS-REPRO) programme ${ }^{3}$ aimed at building food system resilience in protracted crises in some of the least stable regions of the world: South Sudan, Sudan and Somaliland. Staff of these programmes, partner organisations and representatives of their target groups provided data, and participated in on-line workshops to validate research findings.

The research was conducted by following a number of consecutive steps as is illustrated in figure 1: clarity on concepts was required before the three research methodologies could be designed, and tested. Different rounds of drafts and research team meetings allowed for feedback and refinement.

\subsection{What were the outputs?}

This interdisciplinary research tapped into the expertise of different Wageningen University and Research units: Wageningen Economic Research, Biometris, Food and Bio-based Research and the Centre for Development Innovation. The papers produced are as follows:

1. Wigboldus, S. and J. Jacobs. Enhancing the resilience of those most vulnerable to (food) system shocks - Clarifying and unpacking key concepts;

2. Wigboldus, S. and J. Jacobs. Enhancing the resilience of those most vulnerable to (food) system shocks - Towards a sense-making framework and assessment methodology;

3. Roo, N. de and J. van der Lee. Exploring vulnerability and resilience from a multifaceted and systemic perspective - Case studies in Ethiopia and Somaliland;

4. Wattel, C., M. Sopov and M. van Asseldonk. Responsible finance for vulnerable groups under COVID-19;

5. Wattel, C., M. Sopov and M. van Asseldonk. Finance for Resilience Tool (FORTE) - A rapid assessment tool; and

6. Fonteijn, H., J. Groot and X. Guo. Analysing the resilience of food systems with scenario analyses and reverse stress tests - Concepts and an application on the Ethiopian sesame value chain.

\footnotetext{
www.sbnethiopia.org

https://www.wur.nl/en/Research-Results/Research-Institutes/centre-for-development-innovation/show-cdi/FNS-REPRObuilding-food-system-resilience-in-protracted-crises.htm
} 


\section{Overview of the research work}

\subsection{Clarifying and unpacking key concepts}

In their paper "Enhancing the resilience of those most vulnerable to (food) system shocks - Clarifying and unpacking key concepts", Seerp Wigboldus and Judith Jacobs make an inventory of how literature defines five relevant concepts, the first two being different dimensions of the concepts "vulnerability" and "resilience". These are seen to having complimentary characteristics. Related to these concepts, the terminology around "shocks and stresses" and accompanying "risks" are elaborated. The authors also clarify what they mean with "system functions": the desired outcomes of system functioning, and advocate for applying a system approach. The inventory is undertaken from three perspectives:

- who are we talking about when we refer to the most vulnerable in food systems;

- how does this group respond to shocks such as COVID-19; and

- how can we use these concepts to better understand and assist this actor group when looking at them from a systemic perspective?

The five abovementioned concepts make up the basic components of a research framework that has been developed for better understanding of how shocks impact most vulnerable groups (see next section) The concepts can also help in devising response strategies intended to enhance resilience capacity of these groups. As an example of such possible strategy, the role of responsible financing is elaborated.

\subsection{Design of a research framework to better understand vulnerability and coping strategies of the most vulnerable}

Following on their concepts paper, the authors take the next step by capturing the relevant key concepts, and related dimensions and dynamics in a sense-making framework, in the paper: "Enhancing the resilience of those most vulnerable to (food) system shocks - Towards a sense-making framework and assessment methodology". The sense-making framework they propose is illustrated by the following model (figure 2):

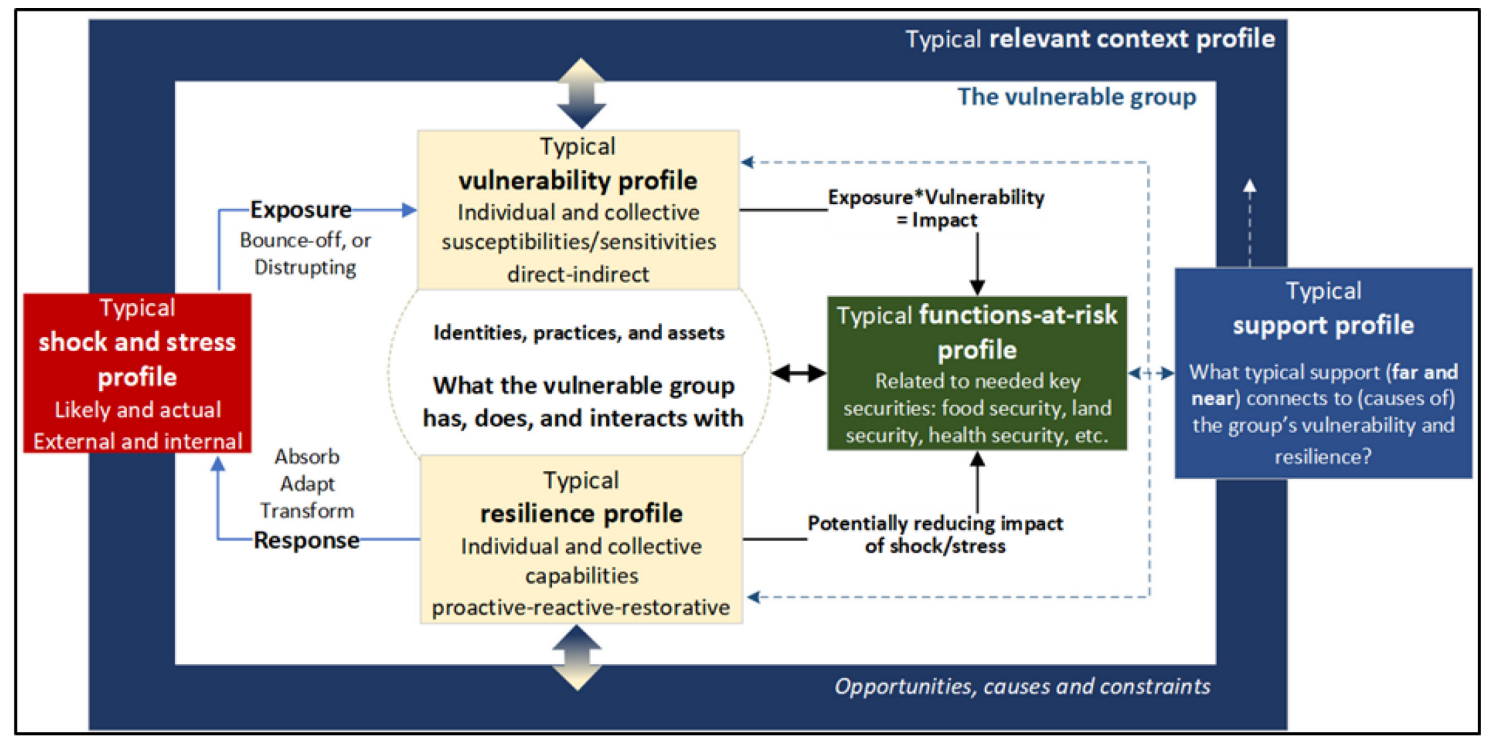

Figure 2 
The model presents all inter-related dimensions of vulnerability and resilience that need consideration, in this case of most vulnerable groups. The authors define these dimensions in terms of "typical profiles". It is accepted that such profile is a kind of average and does not do justice to the variety within social groupings. It means striking a balance between being too specific and making the research top-heavy, and being too broad because that would involve too many exceptions to the "typical". It means working with a mix of qualitative questions and proxy indicators resulting in a research outcome that is "good enough" to serve as a quick-scan method to assesses how resilience of the most vulnerable can be enhanced when systems are in shock. In those conditions it is sometimes necessary to cut corners to come to workable profiles.

The proposed research framework places the following typical profiles in a system perspective:

1. Vulnerable group profile

2. Shock profile - including the dynamic way in which it exposes vulnerability

3. Vulnerability profile - including the dynamic between individual/group vulnerability and the relevant context (influence)

4. Resilience profile - including a) the dynamic between individual/community resilience and the relevant context (influence), and b) the dynamic way in which the group typically responds to particular shocks/stresses

5. System functions-at-risk profile

6. Relevant context profile

a. Key conditions supporting resilience and/or reducing exposure to shocks

b. Key conditions causing vulnerability and/or exacerbating exposure to/impact of shocks

7. Support profile

The seven profiles are assessed on the basis of seven sets of qualitative questions aiming to typify both the systemic vulnerability of a given group as well as their resilience.

The sense-making research methodology is applied in two case studies in Ethiopia and Somaliland, outlined in the next section.

\subsection{Testing the research framework in Ethiopia and Somaliland}

In their paper "Exploring vulnerability and resilience from a multifaceted and systemic perspective Case studies in Ethiopia and Somaliland", Nina de Roo and Jan van der Lee describe the application of the "7 profiles model" outlined above in two case studies. In Ethiopia the most vulnerable group selected were the seasonal migrant labourers in the sesame sector; in Somaliland the unemployed youth from pastoralist communities. In both cases, through a combination of desk work, on-line workshops and focus group discussions facilitated by affiliated in-country project staff, the profiles were filled out. Details and conclusions on vulnerability and coping strategies of the selected case groups can be found in the mentioned paper. Here we would like to reflect on the applicability of the proposed research framework. Five key lessons:

1. The framework helped to identify the various dimensions of vulnerability and resilience to shocks in a systematic manner. This led to better comprehensiveness and nuance in what is still a quick assessment of a by definition complex (food) system;

2. It proved difficult to strike a balance between the need for detail to understand and do justice to all dimensions of vulnerability and resilience, and the anticipated "quickness" of the assessment tool; 
3. Targeting the most vulnerable group for applying the research framework proved difficult. The initially selected vulnerable group proved to be diverse in grades of vulnerability. Prior identification of the most vulnerable grouping deserves a study in itself;

4. The assumption that a particular shock would impact the most vulnerable in a measurable manner proved difficult to maintain. In the case study communities shocks are structural and

permanent. It proved to be impossible to distinguish the effect of a particular shock (e.g COVID19) from other shocks and system stresses such as drought, locust, civil war, structural shortage of arable land. "They are not called shocks but daily reality" as one of the local researchers remarked;

5. Conducting the quick-scan vulnerability assessment ought to be done with active participation of the target group as many research questions are value-laden and tend to be answered with perceptions rather than undisputed facts. While affiliated project staff in Ethiopia and Somaliland were of great help in consultations of the target group, true participation in the study remained limited for the very reason that triggered this research: COVID-19 restrictions.

\subsection{Responsible finance for vulnerable groups under COVID-19}
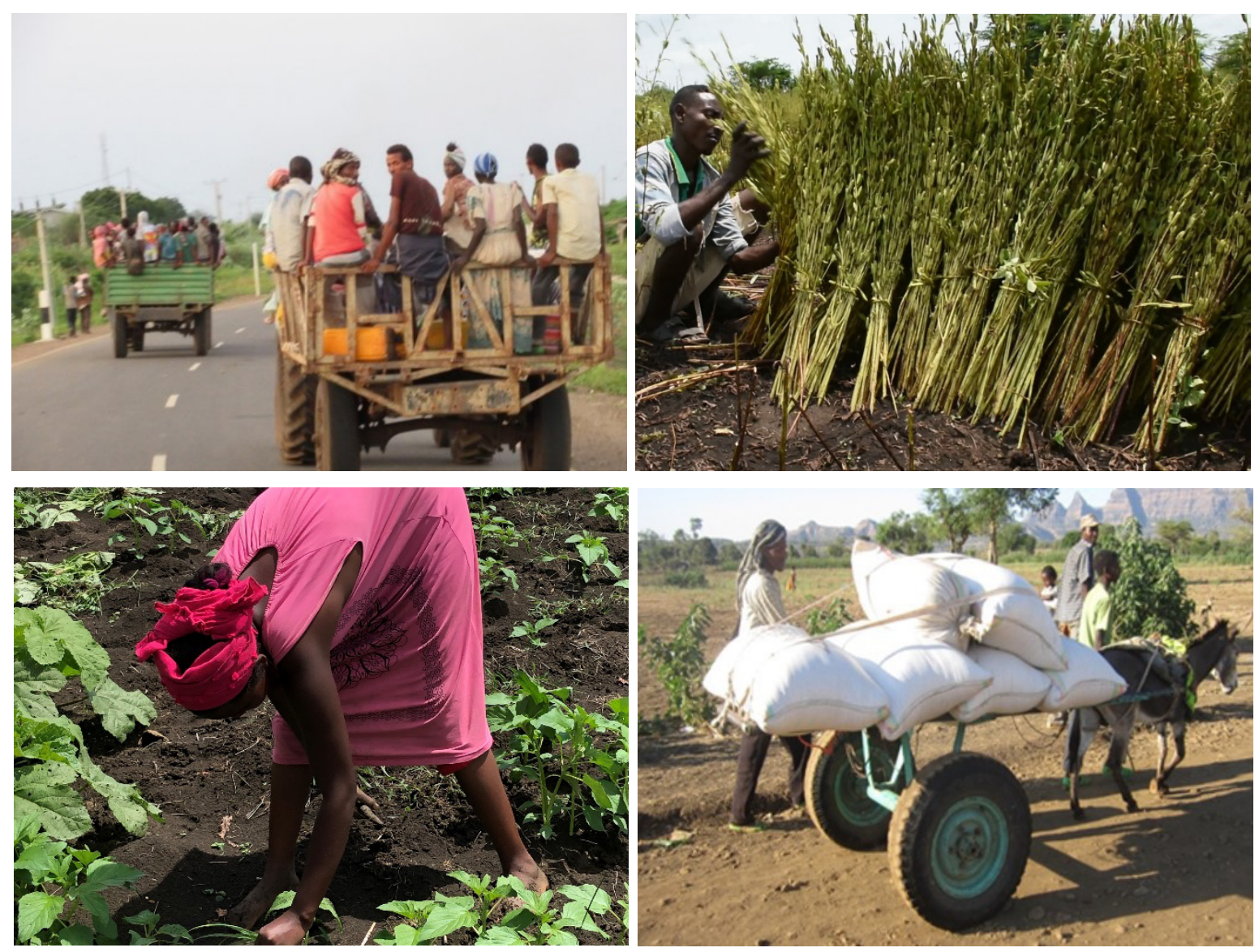

Credits: www.sbnethiopia.org

In their paper "Responsible finance for vulnerable groups under COVID-19", Cor Wattel, Monica Sopov and Marcel van Asseldonk provide a method for exploring how finance plays a role in the vulnerability and resilience of a specific vulnerable group, and what policy and investment options are available to improve their resilience through responsible finance. It led to a tool for rapid assessment to identify opportunities for responsible finance in order to reinforce resilience of specific vulnerable groups against shocks and stresses. Based on a taxonomy of finance options including both risk financing and social protection the "Finance for Resilience Tool" (acronym FORTE) was developed, tested and adjusted based on the two case studies in Somaliland and Ethiopia. 
The FORTE tool helps to assess the opportunities for responsible finance to reinforce resilience of a specific vulnerable actor group in a given country or region. It involves four steps, namely:

- Step 1: Mapping access and use of finance options;

- Step 2: Mapping finance-related causes of vulnerability;

- Step 3: Identifying gaps and assessing their persistence; and

- Step 4: Setting responsible finance priorities.

The testing phase showed that the FORTE tool effectively helps to make a systematic rapid assessment of finance for resilience for the actor group at hand. The tool applies a clear-cut sequence of mapping (steps 1 and 2), gap analysis (step 3) and priority setting (step 4). In the two test cases, the tool was applied in a desk study enriched with insights from the field through expert workshops and focus group discussions respectively. This illustrates that mixed methods are needed to collect relevant insights about this topic. The tool is available in a fill-out version, to facilitate its rapid application by other practitioners and researchers, and can be downloaded:

https://doi.org/10.18174/543746.

\subsection{Using scenario analysis and reverse stress tests to analyse the resilience of food systems}

In their paper "Analysing the resilience of food systems with scenario analyses and reverse stress tests - concepts and an application on the Ethiopian sesame value chain", Hubert Fonteijn, Jim Groot and Xuezhen Guo describe how modelling-based stress-testing and reverse stress-testing might be relevant for high shock, low predictability food systems. The possibilities, and challenges of doing so for such data-poor contexts were explored by developing a conceptual framework for stress tests in the food systems context and proposed the reverse stress testing framework as a complementary approach. Focussing on the case study (seasonal labourers within the Ethiopian Sesame value chain) they applied an Agent Based Model approach to model labour market/wage negotiations between seasonal labourers and farmers. The limited time and limited data made it impossible to extend the exercise into a fully-fledged reverse stress test responding to the COVID-19 crisis that hit the sesame sector in 2020. 


\section{Shocks and stresses are structural, and need to be dealt with}

One year after formulating the idea for this research, global experience has confirmed how essential it is to better understand what shocks the most vulnerable in food systems face, in order to support their coping efforts more effectively. In the space of that year, COVID-19 is making the world face up to the fact that shocks and stresses to food systems are omnipresent, will be around for a long time and need smart, evidence-based responses. In October 2020 the World Bank's Poverty and Shared Prosperity Report concluded that by 2021 over 150 million more people would be pushed into extreme poverty, reversing several decades of progress on the SDGs. Sadly, this has become reality, with for example the IMF concluding that sub-Saharan Africa's economy shrank by an unprecedented $1.9 \%$ in 2020.

For the most vulnerable in food systems, COVID-19 is just the latest shock creating a structural state of pressure from shocks and stresses as trialling the vulnerability assessment methodology in Ethiopia and Somaliland made clear (see the report of Nina de Roo and Jan van der Lee's referred to earlier). The recent Wageningen Economic Research White paper Towards a Future Research Agenda on Food System Resilience (Bakker, Termeer, Steenhuijsen Piters, 2021) confirms that such pressures on food systems, and therefore vulnerable groups, are widespread and for the foreseeable future structural through climate change, political unrest, soil degradation, biodiversity loss, etc.

Enhancing resilience is therefore one of the priorities of the UN Food System Summit - UNFSS Action Track 5: Build resilience to vulnerabilities, shocks and stresses. This track is meant to "work to ensure the continued functionality of sustainable food systems in areas that are prone to conflict or natural disasters [and] protect food supplies from the impacts of pandemics". Importantly, to achieve that all people within a food system must be "empowered to prepare for, withstand, and recover from instability".

A recent comprehensive global assessment of the impacts of COVID-19 on food systems and their actors (Béné et al 2021) concludes that COVID-19, in particle measures put into place to curtail it, have had a structural negative impact on food accessibility and therefore the resilience of many vulnerable actors in LMICs. The review concludes also that despite all the research overall too little is known about food systems resilience to be able to act on it. One key reason is that resilience is studied in too theoretical a manner with too much focus on high-income countries. The result: "...very little is currently known about the different elements that would be necessary to strengthen the resilience of both the actors and the systems in the context of LMICs".

Rapid sector assessments of COVID-19 impacts ${ }^{4}$ by Wageningen's Centre for Development Innovation have highlighted how drawing in sector-wide perspectives point to 'hidden' impacts and unexpected necessary responses needed by the more vulnerable. Assessments need to go beyond listening to those who are better capable of identifying impacts on their own constituencies, and include groups such as informal market vendors and women traders. Such assessments demonstrate that it is possible to build a better picture of vulnerability, provided it is made a priority in research design and implementation.

\footnotetext{
4 See note 1 above.
} 


\section{$4 \quad$ Real-time understanding of vulnerability informing responses for greater resilience}

The Discussion Starter of the Resilience Action Track for the UNFSS 2021 states that our focus needs to lie on the following: "Solutions need to be defined around cross-cutting levers of joined up policy reform, coordinated investment, accessible financing, innovation, traditional knowledge, governance, data and evidence, and empowerment of the most vulnerable". ${ }^{5}$ More specifically, the White paper by Bakker, Termeer and Steenhuijsen Piters identifies four areas for a future food systems resilience research agenda:

1. Shocks and stresses: what kinds are there and how do they affect food systems;

2. Interactions and outcomes, in particular trade-offs between possible responses;

3. Leverage points for resilience building; and

4. Governance: the will and structures to act differently for greater resilience.

Based on the process and findings of our research, this means we now need to work further on HOW to:

a. better understand realities of the more vulnerable in food systems;

b. help the more vulnerable use that understanding to both soften immediate impacts as well as deal with structural causes; and

c. do that in a timely manner.

The outcomes of the research provide steps in the direction of using good science to inform relevant responses:

- Key concepts are made precise and explicit, and therefore workable: resilience, vulnerability, shocks and stresses, risks;

- These are the basis for a robust framework that allows for a systematic assessment of vulnerability in different contexts;

- Field testing demonstrates that it is possible to carry out time-bound, systematic assessments that lead to acceptable, actionable understanding of the new realities of specific actor groups in food systems;

- These assessments can usefully inform compensatory financial measures - one possible key response area --so that they are more relevant to both short and long-term needs; and

- The FORTE tool offers a process for responsible design of possible financial measures.

These findings can be of particular importance to more disaster relief oriented organisations that seek more robust ways of taking stock before undertaking necessary urgent action. This can help them avoid simply not seeing the more vulnerable in food systems, further locking-in more structural causes of shocks and stresses while trying to soften short-term impacts and designing from a needs assessment rather than assumptions of needs. For government agencies funding shock responses, the tools and approaches can be used to more quickly judge what they should prioritize in terms of investments and other responses. Finally, more vulnerable groups - where organised in some way could use this to make their reality known to their surroundings and thus possibly strengthen their agency to influence what is done with them rather than for them.

The shortcomings run into during this first research are inevitable. and need further attention. The following topics in any case would be worthwhile pursuing further in the immediate future:

- Effective means of working with, and thus empowering, the more vulnerable groups needs more methodological consideration. This is particularly necessary in situations of shock, that inevitably impose restrictions on necessary travel, communication, resources, etc.;

UNFSS 2020 
- Key concepts need further clarification and simplification to make them actionable in many different contexts, and in time-efficient manner;

- The assessments must be carried out with implementing parties to find out how they can be more reliable and relevant for better informed, rapid and responsible ways of responding; and

- The frameworks and approaches need to be trialled in a range of situations to be able to evaluate when and where they are of benefit.

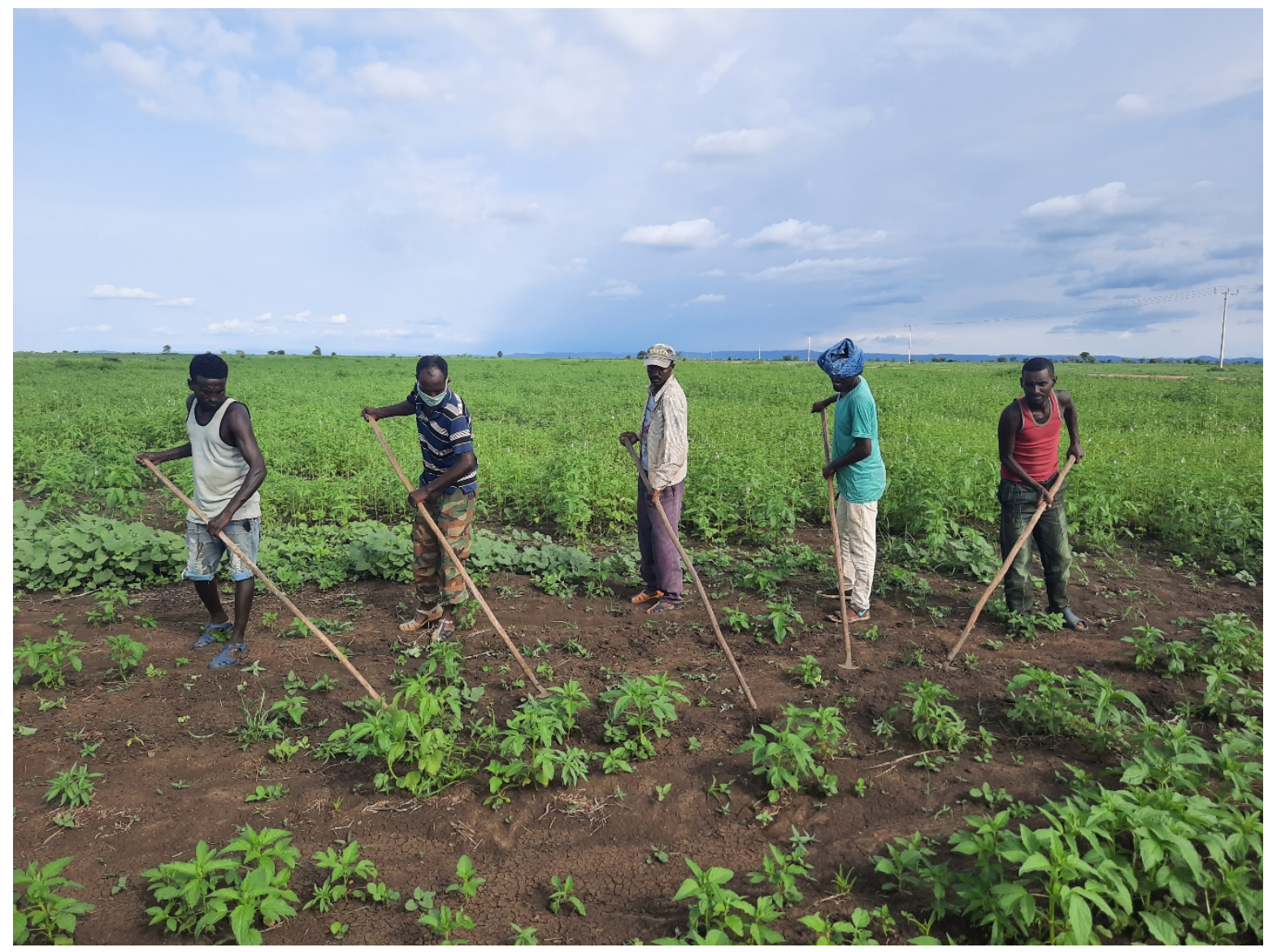

Credits: www.sbnethiopia.org 


\section{References}

Bakker D., E. Termeer and B. Steenhuijsen Piters, 2021. Towards a Future Research Agenda on Food System Resilience Wageningen Economic Research White Paper, Wageningen.

Béné, C., D. Bakker, M. Chavarro Rodriguez, B. Even, J. Melo and Anne Sonneveld, 2021. Impacts of COVID-19 on People's Food Security: Foundations for a more Resilient Food System CGIAR COVID-19 Hub.

Criado Perez, Caroline, 2019. Invisible Women. Exposing data bias in a world designed for men. Vintage Books, London.

Discussion Starter Paper, 2020. Action Track 5: Build resilience to vulnerabilities, shocks and stress. UN Food Systems Summit 2021.

Woodhill, J., Hasnain, S. and Griffith, A., 2020. Farmers and food systems: What future for small scale agriculture? Environmental Change Institute, University of Oxford, Oxford.

Worldbank, 2020. UN/DESA Policy Brief \#81: Impact of COVID-19 on SDG progress: a statistical perspective. 
Wageningen Centre for Development Innovation

Wageningen University \& Research P.O. Box 88

$6700 \mathrm{AB}$ Wageningen

The Netherlands

$\mathrm{T}+31(0) 317486800$

www.wur.eu/cdi

Report WCDI-21-140
Wageningen Centre for Development Innovation supports value creation by strengthening capacities for sustainable development. As the international expertise and capacity building institute of Wageningen University \& Research we bring knowledge into action, with the aim to explore the potential of nature to improve the quality of life. With approximately 30 locations, 6,500 members (5,500 fte) of staff and 12,500 students, Wageningen University \& Research is a world leader in its domain. An integral way of working, and cooperation between the exact sciences and the technological and social disciplines are key to its approach. 



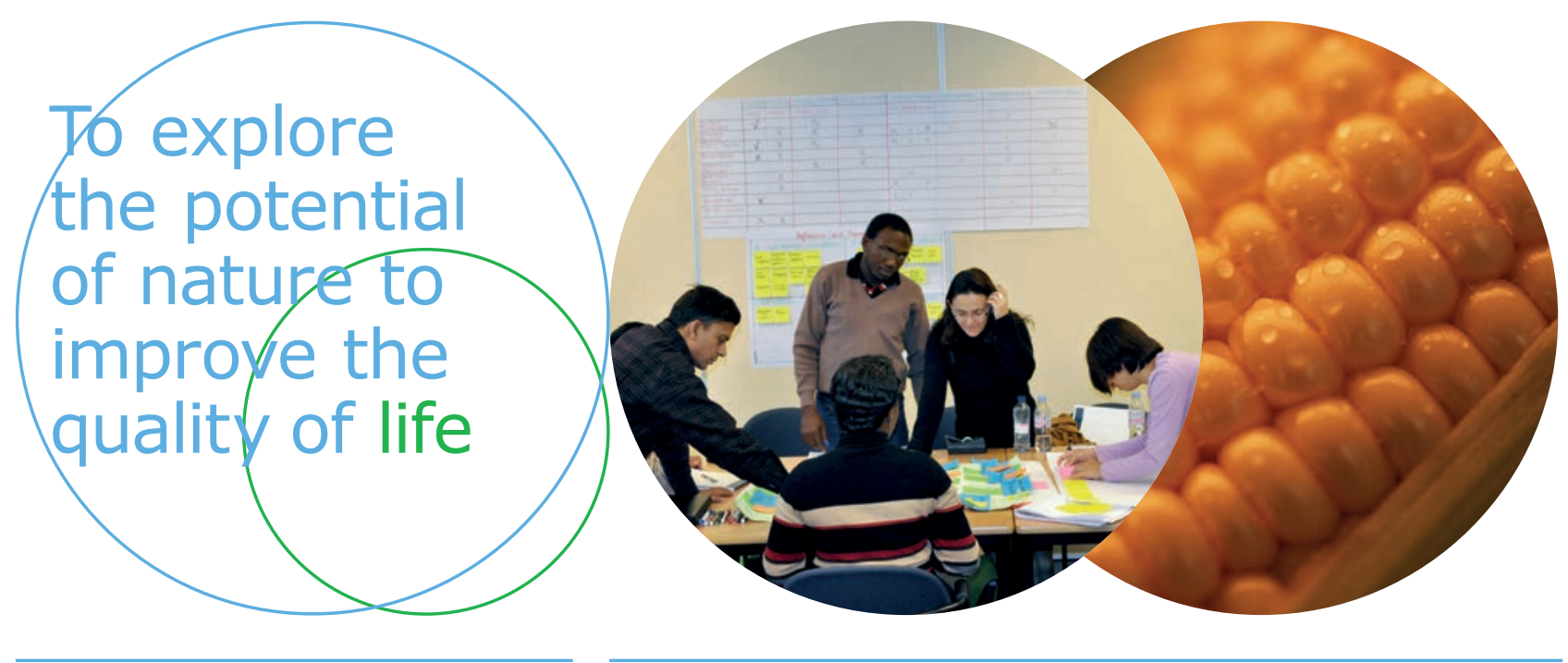

Wageningen Centre for Development Innovation Wageningen University \& Research P.O. Box 88 $6700 \mathrm{AB}$ Wageningen The Netherlands $\mathrm{T}+31$ (o)317 4868 oo www.wur.eu/cdi

Report WCDI-21-140
Wageningen Centre for Development Innovation supports value creation by strengthening capacities for sustainable development. As the international expertise and capacity building institute of Wageningen University \& Research we bring knowledge into action, with the aim to explore the potential of nature to improve the quality of life. With approximately 30 locations, 6,500 members $(5,500 \mathrm{fte})$ of staff and 12,500 students, Wageningen University \& Research is a world leader in its domain. An integral way of working, and cooperation between the exact sciences and the technological and social disciplines are key to its approach. 